\title{
From crisis to healthy farming and food systems
}

\author{
Steve Brescia ${ }^{1}$
}

Accepted: 28 April 2020 / Published online: 18 May 2020

(c) Springer Nature B.V. 2020

In a few short months an urgent question has absorbed people around the world. How and when do we end the COVID 19 pandemic? The answers depend on what actions we take. They also depend on recognizing the profound connections between our human health and the health of our ecosystems, economies, communities and societies. All of these rest on our agricultural and food system.

Groundswell International works with family farming communities in West Africa, the Americas and South Asia to sustainably overcome poverty and improve lives. These communities are accustomed to facing crisis. They are pioneers innovating solutions on the front lines of global challenges. When they experience crises in their farming and ecosystems, created by political and economic dynamics and practices, it often motivates smallholders to organize and develop more agroecological farming and local food systems. Their choice is to change, migrate or perish. Similarly, when epidemics (like cholera in Haiti) or natural disasters (like earthquakes in Haiti and Nepal) strike, we have seen how communities' capacities for resilience allow them to limit damage and recover. So who better to learn from about responding to a crisis like COVID 19, or longer-term crises like climate change and chronic diseases?

Crises hit the most vulnerable the hardest. The World Food Program reports that COVID 19 may double the number of people facing acute hunger by the end of $2020 .{ }^{1}$ People around the world are already facing the devastating impacts of climate change. Non-communicable, chronic diseases tied to the Western diet and excess weight are now the leading cause of death in many countries. Our industrialized agriculture and food system are major contributors to these crises. Communities and social movements we support are reversing the downward cycle of ecological degradation,

This article is part of the Topical Collection: Agriculture, Food \& Covid-19.

Steve Brescia

sbrescia@groundswellinternational.org

1 Groundswell International, Washington, DC, USA poverty and hunger, by promoting agroecology and strengthening local food economies.

Lankoande Francois and his family in eastern Burkina Faso are an example. Like 20 million people in the West African Sahel, they face the collapse of soil fertility and food production, leading to chronic poverty and hunger. In response, they have organized with neighbors and tested ways to regenerate their barren land. They dig small planting pits to hold rainwater, learn rapid composting techniques, access local seeds with a shorter growing season, and regenerate trees on their farms instead of slashing and burning fields. After 4 years, Lankoande and his family have recovered six acres of land, are producing 3.5 times more food, and have enough grain stored for the year, with surplus to sell. They are part of a farmer-to-farmer agroecology network spreading these approaches across 80 villages.

On eroded mountainsides in Central America, Haiti, and the Andes, farmers install soil and water conservation barriers, use cover crops to fix nitrogen and restore organic matter to soils, and diversify farms for improved resilience, production and nutrition. To escape debt and ensure food security, they mobilize assets in savings groups, community grain reserves, and seed banks. Cooperative farmer enterprises and alliances of farmers and consumers are working to rebuild local food markets.

What lessons can we draw as we work to build back better from current crises?

- Human solidarity above self-interest: Positive social change requires trust and organization.

- Regeneration not extraction: Produce in balance with nature, rather than destroying the ecosystems we depend on.

- Healthy farming and food: Link production that is healthy for the planet with consumption that is healthy for people.

\footnotetext{
1 https://insight.wfp.org/covid-19-will-almost-double-people-inacute-hunger-by-end-of-2020-59df0c4a8072
} 
- Ground-up innovation: Provide the right support for farmers and consumers to create sustainable agriculture and food systems.

- Democracy not centralized power: Design farming and food systems based on the interests of people organizing locally for their wellbeing, not the short-term financial interests of concentrated corporate and political power.

Insanity, they say, is doing the same thing and expecting different results. The COVID 19 crisis is now leading to necessary changes in human behavior, economic and political responses, and resource allocations. We must also respond to wider crises and build more agroecological farming and food systems. The creative capacity of the world's smallholders to farm productively with nature instead of against it, and build alliances with all of us who want to eat healthy food, is a powerful force to overcome poverty, hunger, disease and climate change. Let's nurture these ground-up solutions.
Publisher's Note Springer Nature remains neutral with regard to jurisdictional claims in published maps and institutional affiliations.

Steve Brescia is the Executive Director and co-founder of Groundswell International, a network of local NGOs working in ten countries in West Africa, the Americas and South Asia to strengthen communities to build healthy farming and food systems from the ground up. He has over 30 years of experience supporting programs to strengthen agroecology, community-led development, social and economic justice, and grassroots advocacy. Mr. Brescia is the editor of the book 'Fertile Ground: Scaling Agroecology from the Ground Up' (2017, Food First Books). He holds an MA in International Development from American University. 